\title{
How does entrepreneurial failure change an entrepreneur's digital identity? Evidence from Twitter data
}

\author{
Christian Fisch ${ }^{\mathrm{a}, \mathrm{b}, *}$, Jörn H. Block ${ }^{\mathrm{a}, \mathrm{b}}$ \\ ${ }^{a}$ Trier University, Faculty of Management, 54296 Trier, Germany \\ ${ }^{\mathrm{b}}$ Erasmus School of Economics, Erasmus University Rotterdam, P.O. Box 1738, 3000 DR Rotterdam, the Netherlands
}

\section{A R T I C L E I N F O}

\section{Keywords:}

Digital identity

Failure

Twitter

Entrepreneur

Text analysis

Digital footprints

LIWC

\begin{abstract}
A B S T R A C T
We assess whether and how entrepreneurs' digital identities change in response to entrepreneurial failure based on a sample of 760 entrepreneurs who experienced failure. We analyze a longitudinal dataset of Twitter messages before, during, and after a business failure with a language-based method of computerized text analysis. The results of our explorative research indicate that the financial, social, and psychological consequences of failure are reflected in entrepreneurs' Tweets and lead to changes in their digital identities. Among others, entrepreneurs' language decreases in emotional tone and indicates increased psychological distress. Simultaneously, we observe higher levels of self-assurance and reflection after failure. We conclude by outlining the potential of using Twitter-generated digital footprints in future entrepreneurship research.
\end{abstract}

\section{Executive summary}

Entrepreneurs' conduct on social media sites, such as Twitter, is increasingly important for venture success in today's digital world. An essential construct in this regard is the entrepreneur's digital identity, which refers to the entrepreneur's online selfrepresentation and shapes how the entrepreneur is perceived by and interacts with stakeholders (e.g., Fischer and Reuber, 2014; Smith et al., 2017).

While identities are generally stable over time (Cardon et al., 2009), critical events can lead to identity changes. Since entrepreneurs often see their venture as an integral part of their identity (e.g., Shepherd, 2003; Ucbasaran et al., 2013), the venture's failure is a critical event that can prompt such identity changes. So far, however, little is known about whether and how events such as failure affect entrepreneurs' digital identities.

To fill this gap, we draw on entrepreneurs' Twitter profiles and apply a computerized text analysis to entrepreneurs' Tweets to operationalize their digital identity via a variety of linguistic and psychological dimensions. We analyze Tweets from 760 entrepreneurs who experienced failure. Our results indicate that the financial, social, and psychological consequences of failure are indeed reflected in entrepreneurs' Tweets and lead to changes in their digital identity. We highlight that a failure's consequences for entrepreneurs can be both negative and positive. For example, we find that entrepreneurs increasingly talk about work and money after experiencing failure, potentially indicating financial and psychological distress. Additionally, we find that the entrepreneur's language becomes less emotional and affective, indicating self-distancing. Simultaneously, the language used becomes more reflective and self-assured after failure.

\footnotetext{
* Corresponding author at: Trier University, Faculty of Management, 54296 Trier, Germany.

E-mail addresses: cfisch@uni-trier.de (C. Fisch), block@uni-trier.de (J.H. Block).
} 
Our findings extend the nascent research on entrepreneurs' digital identities with longitudinal insights. We show that digital identities are not constant over time and change in response to entrepreneurial failure. Additionally, our findings provide fresh insights to the established literature on entrepreneurial failure. Specifically, we provide a robust and nuanced analysis of the effect of failure and highlight specific aspects of an entrepreneur's digital identity that are negatively or positively affected by failure. Our findings have practical implications because we show that failure is not an unequivocally positive or negative event. Since our research is exploratory, we conclude with a detailed account of how future entrepreneurship research can make use of data from digital footprints.

\section{Introduction}

Entrepreneurs increasingly use social media sites to manage their personal and business networks. Hence, entrepreneurs' digital identities (i.e., their digital self-representation on social media sites) are increasingly important for a venture's success in today's digital age (e.g., Nambisan, 2017; Smith et al., 2017). Recent studies agree that research on digital identities is both highly relevant and timely (e.g., Fischer and Reuber, 2014; Smith and Smith, 2019).

A better understanding of entrepreneurs' digital identities is crucial because identity-consistent behavior has a critical motivational function for entrepreneurs (e.g., Cardon et al., 2005; Wry and York, 2017). While identities are generally enduring (Cardon et al., 2009), prior research indicates that identities can be modified, for example, in response to incisive external events (Jain et al., 2009). Business failure is an incisive event for entrepreneurs (e.g., Shepherd, 2003; Ucbasaran et al., 2013). Since entrepreneurs often see their venture as part of their identity, the venture's success or failure reflects on the entrepreneur (e.g., Cardon et al., 2005; Shepherd and Haynie, 2009) and can prompt identity modifications. In this study, we bridge research on entrepreneurs' digital identities and research on entrepreneurial failure to assess the following research question: How does an entrepreneur's digital identity change in response to entrepreneurial failure?

To answer this question, we use entrepreneurs' Twitter profiles to operationalize shifts in their digital identities in response to entrepreneurial failure. Our explorative results indicate that the consequences of failure are indeed reflected in entrepreneurs' Tweets and lead to changes in their digital identities.

Our study's main contribution is twofold. First, we contribute to research on entrepreneurs' digital identities (e.g., Fischer and Reuber, 2011; Obschonka et al., 2017; Smith et al., 2017). While this research has mostly assessed cross-sectional differences in digital identities, we analyze digital identities in a longitudinal setting. Specifically, we document that critical "offline" events (i.e., entrepreneurial failure) can lead to changes in entrepreneurs' digital identities. Additionally, we capture entrepreneurs' digital identities in a fine-grained way via a variety of linguistic and psychological dimensions and highlight the need for a differentiated assessment of different identity components. Second, our explorative findings contribute to research on entrepreneurial failure (e.g., Cope, 2011; Shepherd, 2003; Ucbasaran et al., 2013). By using longitudinal data from Twitter, we document the profound consequences of entrepreneurial failure. We also contribute to this research by illustrating and quantifying how entrepreneurs respond to failure over time.

By drawing on a large-scale, Twitter-based language analysis, our exploratory study also responds to a recent editorial by Wiklund et al. (2019), who encourage the use of alternative analytical techniques based on longitudinal designs to generate novel insights and move entrepreneurship research forward. In their recent editorial on the value of exploratory research in entrepreneurship, Wennberg and Anderson (2019) highlight that the primary purpose of explorative research is to generate new insights that future research can build on. While we link our findings to existing research in the domains of entrepreneurial failure and digital identities, our study intends to serve as a basis for future applications and more theory-driven analyses. To stimulate future research using similar approaches, we make large parts of our data and statistical analyses publicly available. ${ }^{1}$

Finally, our findings are of practical relevance. Even though entrepreneurial failure often involves societal stigmatization (e.g., Cardon et al., 2011; Simmons et al., 2014), failure is now more commonly seen as a necessary component for future success. While entrepreneurship research often highlights the positive side of failure (e.g., Cope, 2011; Ucbasaran et al., 2013), these positive aspects now also increasingly find their way into practice-oriented publications (e.g., "Increase your return to failure", Birkinshaw and Haas, 2016). Our results put these findings into perspective and empirically show that the consequences of failure for an entrepreneur's selfperception and digital identity can be both positive and negative. Thus, it is dangerous to either stigmatize or romanticize business failure.

\section{Literature review}

\subsection{Research on entrepreneur's digital identities}

Information based on an individual's digital self-representation is commonly referred to as a digital footprint, which can be used to assess the individual's digital identity (e.g., Obschonka et al., 2017; Youyou et al., 2015). The analysis of digital footprints is common in psychology (in particular in personality psychology) and computer science (e.g., Chen et al., 2017; Kosinski et al., 2013; Youyou et al., 2015). This research shows that methods based on digital footprints can provide accurate information about individuals' actual identities. Additionally, this research shows that individuals' online and offline identities are often very similar (e.g.,

\footnotetext{
${ }^{1}$ Our online appendix, data, and analyses are available here: https://osf.io/w2ags/
} 
Gosling et al., 2011; Kosinski et al., 2013).

Several entrepreneurship studies highlight the potential applications of information based on digital footprints (e.g., Nambisan, 2017; Smith et al., 2017). Existing studies draw on digital footprints to analyze the acquisition of resources in entrepreneurial ventures (Smith and Smith, 2019), the accumulation of social capital in an online context (Smith et al., 2017), or an entrepreneurial venture's communication strategies in a predominantly digital setting (Fischer and Reuber, 2011, 2014). While these studies show that research based on digital footprints is relevant, they mention entrepreneurs' digital identities rather parenthetically. Hence, entrepreneurship research on digital identities is still in its infancy.

A stream of the literature that focuses more narrowly on entrepreneurs' digital identities uses methods based on digital footprints to capture an entrepreneur's personality and digital identity. For example, Obschonka et al. (2017) and Obschonka and Fisch (2018) use a language-based analysis of Twitter data to infer the digital identities of entrepreneurs to compare them to those of managers. Similarly, Tata et al. (2017) analyze the language of entrepreneurs via Twitter and compare it to a general population sample. Other related studies explore the digital footprints of business angels (Block et al., 2019), CEOs (Lee et al., 2017), and chief marketing officers (Winkler et al., 2020).

We build on these studies and assess whether and how entrepreneurial failure changes entrepreneurs' digital identities. While prior studies mostly use cross-sectional research designs, our study explores digital footprints to answer longitudinal or processrelated entrepreneurship research questions.

\subsection{Research on the consequences of entrepreneurial failure}

\subsubsection{Financial consequences}

Typically, failure leads to a reduction or loss of income and an accumulation of debt for the entrepreneur (Ucbasaran et al., 2013). This financial distress can have severe implications for entrepreneurs, which include difficulties retaining their lifestyle, the necessity of selling assets or borrowing money, and dealing with personal bankruptcy proceedings (e.g., Cope, 2011; Singh et al., 2007).

The financial consequences of failure vary. Entrepreneurial failure can lead to substantial and difficult-to-overcome personal debt (Cope, 2011). In contrast, entrepreneurs with a well-diversified portfolio, high personal wealth, or attractive outside options may incur lower financial consequences of failure (Arora and Nandkumar, 2011). Due to the substantial negative outcomes, numerous studies investigate the association between bankruptcy laws and entrepreneurship (e.g., Peng et al., 2010). While some countries provide little protection for entrepreneurs, other countries allow entrepreneurship with limited personal liability. Studies generally show that entrepreneur-friendly bankruptcy laws encourage entrepreneurship by limiting the financial consequences of failure, especially for risk-averse entrepreneurs (e.g., Lee et al., 2011).

\subsubsection{Social consequences}

Social consequences can emerge from business failure because the loss of a venture often results in a loss of social relationships and a lower social standing for entrepreneurs (e.g., Ucbasaran et al., 2013). For example, Cope (2011) and Singh et al. (2007) associate entrepreneurial failure with marriage problems and divorces. More generally, these studies also describe a decreasing quality of the entrepreneur's relationships with close friends and business contacts in the aftermath of failure.

This deterioration of personal and professional relationships is often associated with a societal stigmatization of entrepreneurial failure, which describes a devaluation of the entrepreneur's social identity (e.g., Shepherd and Haynie, 2011; Singh et al., 2015). Stigmatization can lead to negative discrimination in terms of future employment opportunities or access to resources (e.g., capital), especially in the case of bankruptcy (e.g., Cope, 2011; Shepherd and Haynie, 2011). Therefore, the societal stigma of entrepreneurial failure is a significant deterrent to entrepreneurial activity (e.g., Simmons et al., 2014; Singh et al., 2007). Failure can also lead to a self-stigmatization because entrepreneurs often intertwine their identity with the venture and its development. This self-stigmatization of entrepreneurs further increases the social consequences of failure because it can lead to social distancing (e.g., Cope, 2011; Singh et al., 2015).

\subsubsection{Psychological consequences}

The psychological consequences of entrepreneurial failure refer to emotional and motivational effects. Many studies document a negative emotional response to entrepreneurial failure and describe that failure can decrease the well-being of the individuals involved. This affective dimension of failure is often associated with grief, which is an umbrella term encompassing a range of negative emotional responses (e.g., Shepherd, 2003; Shepherd et al., 2009). More specifically, prior research describes failure as an emotionally exhaustive and draining event that can lead to extreme levels of stress, guilt, depression, anxiety, anger, exhaustion, and high blood pressure (e.g., Cope, 2011; Jenkins et al., 2014; Singh et al., 2007). Relatedly, this adverse emotional reaction can be amplified by negative reactions in other spheres, such as an individual's professional and social environment, including investors, employees, and family. Furthermore, the psychological consequences of failure can have a detrimental effect on an individual's motivation because failure can lead to a sense of helplessness and lower levels of self-esteem that hinder future task performance (e.g., Jenkins et al., 2014; Ng and Jenkins, 2018; Shepherd, 2003; Singh et al., 2007).

However, entrepreneurial failure is rarely described as a purely negative event from a psychological perspective. Instead, prior research frequently highlights that entrepreneurial failure provides the possibility for individual learning and growth to occur (e.g., Cope, 2011; Shepherd, 2003; Shepherd et al., 2009). For example, Cardon and McGrath (1999) acknowledge that many entrepreneurs view past failures as learning journeys and crucial elements of their experience bases. Therefore, studies in entrepreneurship often focus on the aftermath of business failure to assess the coping mechanisms and grief-recovery strategies of the 
individuals involved (e.g., Cope, 2011; Mandl et al., 2016; Shepherd, 2003; Jenkins et al., 2014). Business failure can also have positive motivational effects and lead to increased self-reassurance (e.g., Ng and Jenkins, 2018; Ucbasaran et al., 2013).

\section{Empirical approach}

\subsection{Computerized text analysis with Linguistic Inquiry and Word Count (LIWC)}

We assess entrepreneurs' digital identities via their text and language. Language has a high psychological value since written or spoken words provide information on individuals' thoughts, beliefs, emotions, relationships, and personalities (e.g., Boyd et al., 2019; Tausczik and Pennebaker, 2010). Today, large amounts of text can be analyzed in a computerized way via closed-vocabulary, wordcounting approaches (Park et al., 2015; Schwartz et al., 2013). Linguistic Inquiry and Word Count (LIWC) is the most popular software for such computerized text analysis (Pennebaker et al., 2015).

LIWC is dictionary-based and calculates $>90$ output variables for any given text. These variables comprise linguistic and psychological dimensions. The latest version (i.e., LIWC2015) contains dictionaries that comprise 6400 words, word stems, and emoticons (for more information, see Pennebaker et al., 2015). For example, to measure "positive emotions", LIWC2015 uses a dictionary that contains 620 individual terms (i.e., target words), such as "agree", "fantastic", and "wonderful". The software then captures the occurrence of these terms and calculates a composite "positive emotions" value. Note that an advantage of LIWC2015 is the inclusion of "netspeak" language, which is common in social media. For example, LIWC2015 counts ":)" and "lol" (= laughing out loud) as indicators of positive emotions.

Numerous studies in psychology employ LIWC (e.g., Boyd et al., 2019; Park et al., 2015; Tausczik and Pennebaker, 2010). Inspired by research in psychology, management research uses LIWC to document associations between language and important strategic outcomes (e.g., Nadkarni and Chen, 2014; Zavyalova et al., 2012). Within the entrepreneurship field, LIWC has been mainly used in entrepreneurial orientation research (e.g., Wolfe and Shepherd, 2015) and in entrepreneurial finance (e.g., Fisch, 2019; Parhankangas and Renko, 2017).

\subsection{Analyzing entrepreneurs' Tweets with LIWC}

We apply LIWC to text retrieved from Twitter. Twitter is a widely used social media network that allows users to broadcast short messages ("Tweets") to a broad audience (e.g., Fischer and Reuber, 2011). Social network sites such as Twitter are increasingly used by entrepreneurs and have significantly changed how entrepreneurs interact with their stakeholders (e.g., Fischer and Reuber, 2011; Smith et al., 2017). As such, Twitter presents a promising data source for entrepreneurship research.

Individuals willingly and voluntarily publish information about themselves on Twitter. On average, $>500$ million messages are broadcasted on Twitter each day. From a language analysis perspective, Twitter thus creates an unprecedented amount of text that is publicly available and can be analyzed (Schwartz et al., 2013).

Moreover, the personal usage of Twitter by individuals provides a unique data source on individuals who are usually difficult to reach, such as entrepreneurs. For example, recent studies using Twitter data explore the personalities and psychological characteristics of superstar entrepreneurs and managers (e.g., Obschonka and Fisch, 2018; Obschonka et al., 2017), business angels (Block et al., 2019), CEOs (Lee et al., 2017), and CMOs (Winkler et al., 2020). These studies indicate that the combination of Twitter data and language analysis enables fresh insights into research questions that were previously difficult to assess with conventional research methods and data sources.

Finally, Twitter data is available in a longitudinal format. So far, quantitative studies on entrepreneurial failure have mostly relied on cross-sectional data collected in the aftermath of failure. This gives rise to a potential recall bias and limits causal inferences. Additionally, a person's psychological makeup impacts how he or she experiences failure (e.g., Jenkins et al., 2014; Ucbasaran et al., 2013). In practice, however, an empirical design that accounts for such biases is difficult to realize because it would require data obtained before and after a failure event. Since entrepreneurs often use Twitter personally, they frequently begin using Twitter before a failure occurs and continue to do so after the failure. Tweets have a precise timestamp so that it is possible to differentiate Tweets sent before, during, and after a failure, which enables an assessment of the effects of failure in a robust empirical design.

\section{Data and variables}

\subsection{Data}

We use Crunchbase (www.crunchbase.com) to identify our sample of entrepreneurs who experienced failure. Crunchbase is one of the premier databases on new ventures and is operated by one of the world's leading information platforms on entrepreneurial ventures, TechCrunch (Ter Wal et al., 2016). The data in Crunchbase are provided by community contributors, public sources, and other data providers. Crunchbase then validates the data accuracy with the help of machine learning algorithms and data analysts that curate the data manually (Crunchbase, 2019). As a result, prior research describes Crunchbase as a data source with high reliability, high recency, and broad coverage (e.g., Block et al., 2019; Homburg et al., 2014; Ter Wal et al., 2016).

An additional strength of Crunchbase is that it includes information on ventures and the individuals associated with those ventures, enabling an accurate matching of individual-level and venture-level information. We use this approach to combine information at the individual level (e.g., entrepreneur's personal Twitter account) with company-level information (e.g., whether and 
when a venture was closed).

On June 15th, 2019, we retrieved a list of all entrepreneurs who had founded at least one company that was eventually closed (i.e., before June 15th, 2019). The initial sample contained 7878 individuals. We extracted all personal information available on these individuals, such as gender, location, and personal Twitter accounts. We also retrieved data on their founded ventures, which includes location data and funding information. We eliminated duplicates (e.g., persons with multiple accounts in Crunchbase), reducing the sample to 7341 individuals. Excluding individuals without Twitter accounts further reduced the sample to 2929 entrepreneurs. We then retrieved all Tweets (i.e., messages broadcasted on Twitter) by these entrepreneurs via Twitter's API, resulting in a dataset of $>2.1$ million Tweets.

To capture the effect of failure in a nuanced way, we consider three periods of time and divide the sample of Tweets accordingly for each entrepreneur. The three time periods are as follows: (1) > 90 days before the failure (before failure), (2) 90 days or less before the failure and 90 days or less after the failure (during failure), and (3) $>90$ days after the failure (after failure). ${ }^{2}$

Our sample was further reduced for multiple reasons. We initially cleaned the Twitter data (Obschonka and Fisch, 2018; Obschonka et al., 2017) by excluding links and name tags. Additionally, LIWC requires a minimum number of words to derive meaningful results. Since we require a minimum number of words per period for our analyses, we had to exclude individuals with $<50$ words tweeted in each period. Finally, LIWC can only process English text. Since our sample of entrepreneurs is international, some individuals in our dataset tweeted in other languages, producing biased LIWC scores. To exclude these individuals, we used LIWC's dictionary measure, which quantifies the percentage of text LIWC was able to read and process. We excluded entrepreneurs with $<50 \%$ processable text.

Our final sample comprises 760 entrepreneurs who experienced a business failure and used Twitter before, during, and after failure. We analyzed each entrepreneur's Tweets in LIWC, yielding a separate set of LIWC scores for the periods before, during, and after failure. The amount of information processed in our text analysis is substantial; on average, we analyzed 7066 words before failure, 675 words during failure, and 5523 words after failure per entrepreneur.

\subsection{Variables}

\subsubsection{Dependent variables: Linguistic and psychological variables (LIWC)}

LIWC2015 (version 1.6.0) calculates 93 output variables that can be distinguished into linguistic and psychological variables. The linguistic variables include general language descriptors (e.g., words per sentence), standard linguistic dimensions (e.g., personal pronouns, adverbs), informal language markers (e.g., swear words, netspeak), and punctuation counts (e.g., commas, question marks). The psychological variables refer to word categories that correspond to psychological constructs. These variables include summary variables (e.g., analytical thinking, emotional tone), psychological processes (e.g., affective processes, social processes), and personal concern categories (e.g., work, death).

LIWC is structured hierarchically. For example, the category "affective processes" (tier 1) comprises the subcategories "positive emotion" and "negative emotion" (tier 2). "Negative emotion", in turn, comprises the subcategories "anxiety", "anger", and "sadness" (tier 3). In our following analyses, we focus on LIWC's linguistic and psychological constructs at the highest hierarchical level (tier 1) and use them as our dependent variables. Additional analyses using all LIWC variables are included in our online appendix. ${ }^{3}$

\subsubsection{Independent variables: before, during, and after failure}

Various definitions and operationalizations of entrepreneurial failure exist. In a recent review of research on venture survival and failure, Josefy et al. (2017) find that the discontinuation of a company's operations is the most common proxy for venture failure. This is especially true in the early stage context of entrepreneurship, in which the continuation of operations is often described as entrepreneurs' primary goal (e.g., Paik, 2014). Hence, we operationalize entrepreneurial failure via the discontinuation (i.e., closure) of a company founded by the respective entrepreneur, as indicated in Crunchbase. ${ }^{4}$

Prior research also highlights that entrepreneurial failure does not occur at a single point in time. Instead, failure is a process that can affect entrepreneurs well before and after the actual date of closure (e.g., Cope, 2011; Ucbasaran et al., 2013). We distinguish the periods before failure (i.e., > 90 days before failure), during failure (i.e., 90 days or less before failure and 90 days or less after failure, and after failure (i.e., $>90$ days after failure). We construct a dummy variable for each period to quantify differences over time in our multivariate analyses.

\footnotetext{
${ }^{2}$ While we were not able to identify any specific information on the exact timing of the failure process in prior research, we choose this temporal segmentation because the process and consequences of failure are often referred to in terms of months instead of years (Cope, 2011; Singh et al., 2007). We extend the period during failure to 180 days before failure and 180 days after failure in a robustness check (Section 5.3.2). The data restrictions described in Section 6.3 prohibit a more fine-grained temporal segmentation.

${ }^{3}$ The online appendix is available here: https://osf.io/w2ags/

${ }^{4}$ Notice, however, that Josefy et al. (2017) recommend a multidimensional and non-binary conceptualization of failure. We use a more restrictive operationalization of failure in a robustness check in Section 5.3.3.
} 
Table 1

Brief descriptions and mean values of LIWC's linguistic and psychological variables.

\begin{tabular}{|c|c|c|c|c|c|c|}
\hline \multirow[b]{2}{*}{ Variable } & \multirow[b]{2}{*}{ \# Target words (examples) } & \multirow{2}{*}{$\begin{array}{l}\text { Overall values } \\
\text { Mean (SD) }\end{array}$} & \multicolumn{3}{|c|}{ Mean values over time } & \multirow[b]{2}{*}{$\begin{array}{l}\text { p-value } \\
\text { (ANOVA) }\end{array}$} \\
\hline & & & Before failure & During failure & After failure & \\
\hline \multicolumn{7}{|l|}{ Linguistic variables } \\
\hline \multicolumn{7}{|l|}{ General language descriptors } \\
\hline Words per sentence & - & $15.48(12.45)$ & 14.92 & 16.00 & 15.52 & 0.24 \\
\hline Words $>6$ letters & - & $20.30(4.53)$ & 20.08 & 20.30 & 20.52 & 0.18 \\
\hline Dictionary words & - & $75.80(6.57)$ & 75.65 & 75.68 & 76.06 & 0.39 \\
\hline \multicolumn{7}{|l|}{ Linguistic dimensions } \\
\hline Total function words & 491 (it, to, no, very) & $41.21(5.81)$ & 40.86 & 40.91 & 41.85 & 0.00 \\
\hline Common verbs & 1000 (eat, come, carry) & $13.58(3.08)$ & 13.73 & 13.53 & 13.46 & 0.21 \\
\hline Common adjectives & 764 (free, happy, long) & $5.11(1.42)$ & 5.04 & 5.19 & 5.09 & 0.12 \\
\hline Comparisons & 317 (greater, best, after) & $1.94(0.92)$ & 1.85 & 1.93 & 2.05 & 0.00 \\
\hline Interrogatives & 48 (how, when, what) & $1.35(0.71)$ & 1.31 & 1.36 & 1.37 & 0.23 \\
\hline Numbers & 36 (second, thousand) & $2.23(1.49)$ & 2.31 & 2.25 & 2.13 & 0.07 \\
\hline Quantifiers & 77 (few, many, much) & $1.83(0.84)$ & 1.74 & 1.83 & 1.91 & 0.00 \\
\hline \multicolumn{7}{|l|}{ Informal language } \\
\hline Informal language & 380 (damn, btw, ok) & $2.18(1.43)$ & 2.46 & 2.23 & 1.83 & 0.00 \\
\hline \multicolumn{7}{|l|}{ Punctuation } \\
\hline Total punctuation & - & $28.32(7.40)$ & 29.90 & 28.71 & 26.35 & 0.00 \\
\hline \multicolumn{7}{|l|}{ Psychological variables } \\
\hline \multicolumn{7}{|c|}{ Psychological summary variables } \\
\hline Analytical thinking & - & $80.37(13.21)$ & 81.35 & 79.63 & 80.13 & 0.03 \\
\hline Clout & - & $67.08(13.63)$ & 67.78 & 66.25 & 67.20 & 0.09 \\
\hline Authentic & - & $40.85(18.23)$ & 42.63 & 41.45 & 38.46 & 0.00 \\
\hline Emotional tone & - & 81.15 (20.49) & 84.18 & 77.98 & 81.30 & 0.00 \\
\hline \multicolumn{7}{|l|}{ Psychological processes } \\
\hline Affective processes & 1,393 (happy, cried) & $6.80(2.04)$ & 6.86 & 6.88 & 6.68 & 0.11 \\
\hline Social processes & 756 (mate, talk, they) & $8.21(2.52)$ & 8.26 & 8.17 & 8.19 & 0.74 \\
\hline Cognitive processes & 797 (cause, know, ought) & $9.41(2.77)$ & 9.14 & 9.32 & 9.76 & 0.00 \\
\hline Perceptual processes & 436 (look, heard, feeling) & $2.51(1.30)$ & 2.60 & 2.55 & 2.37 & 0.00 \\
\hline Biological processes & 748 (eat, blood, pain) & $1.55(1.23)$ & 1.68 & 1.57 & 1.40 & 0.00 \\
\hline Drives & 1,103 (ally, win, superior) & $8.39(2.18)$ & 8.30 & 8.42 & 8.44 & 0.40 \\
\hline Relativity & 977 (area, bend, exit) & $14.22(2.89)$ & 14.63 & 14.22 & 13.80 & 0.00 \\
\hline \multicolumn{7}{|l|}{ Personal concerns } \\
\hline Work & 444 (job, majors, xerox) & $4.00(2.17)$ & 3.90 & 4.01 & 4.08 & 0.26 \\
\hline Leisure & 296 (cook, chat, movie) & $1.89(1.30)$ & 2.07 & 1.91 & 1.69 & 0.00 \\
\hline Home & 100 (kitchen, landlord) & $0.30(0.36)$ & 0.30 & 0.30 & 0.29 & 0.74 \\
\hline Money & 226 (audit, cash, owe) & $1.48(1.24)$ & 1.40 & 1.50 & 1.53 & 0.10 \\
\hline Religion & 174 (altar, church) & $0.16(0.25)$ & 0.16 & 0.17 & 0.16 & 0.72 \\
\hline Death & 74 (bury, coffin, kill) & $0.16(0.29)$ & 0.14 & 0.16 & 0.18 & 0.02 \\
\hline
\end{tabular}

Notes: $N=2280$ (760 entrepreneurs with before, during, and after values each). Information on LIWC is taken from LIWC 2015's language manual, which also provides information on each constructs' reliability and validity (Pennebaker et al., 2015). Some categories (e.g., general language, punctuation) are not based on a dictionary of words but represent count indicators. This table only shows tier 1 variables. The full table is displayed in the online appendix in Table OA.II.1a and $1 \mathrm{~b}$.

\section{Results}

\subsection{Descriptive statistics}

Table 1 summarizes the linguistic and psychological variables included in LIWC and gives an overview of the target words used to operationalize each variable. Additionally, Table 1 displays each variable's overall mean value and standard deviation. To explore the differences across the three time periods before, during, and after failure, Table 1 then lists each variable's mean value across the different temporal segments. The final column contains the p-values obtained from an analysis of variance (ANOVA). Our online appendix (Tables OA.II.1 $\mathrm{a}$ and $\mathrm{b}$ ) displays the full table that includes all of LIWC's variables, along with further information on LIWC's hierarchical structure.

The results of the ANOVA document significant differences over time for multiple language variables. Regarding the standard linguistic dimensions reflective of entrepreneurs' grammar and sentence structures, Table 1 shows that entrepreneurs use more function words $(\mathrm{p}=.00)$, comparisons $(\mathrm{p}=.00)$, and quantifiers $(\mathrm{p}=.00)$ during and after failure. In contrast, entrepreneurs tend to use fewer words referring to numbers $(\mathrm{p}=.07)$, less informal language $(\mathrm{p}=.00)$, and less punctuation $(\mathrm{p}=.00)$ during and after failure.

Similar differences exist for LIWC's psychological variables. Concerning the psychological summary variables, the results indicate that entrepreneurs show lower levels of analytical thinking $(p=.03)$, clout $(p=.09)$, authenticity $(p=.00)$, and emotional tone 


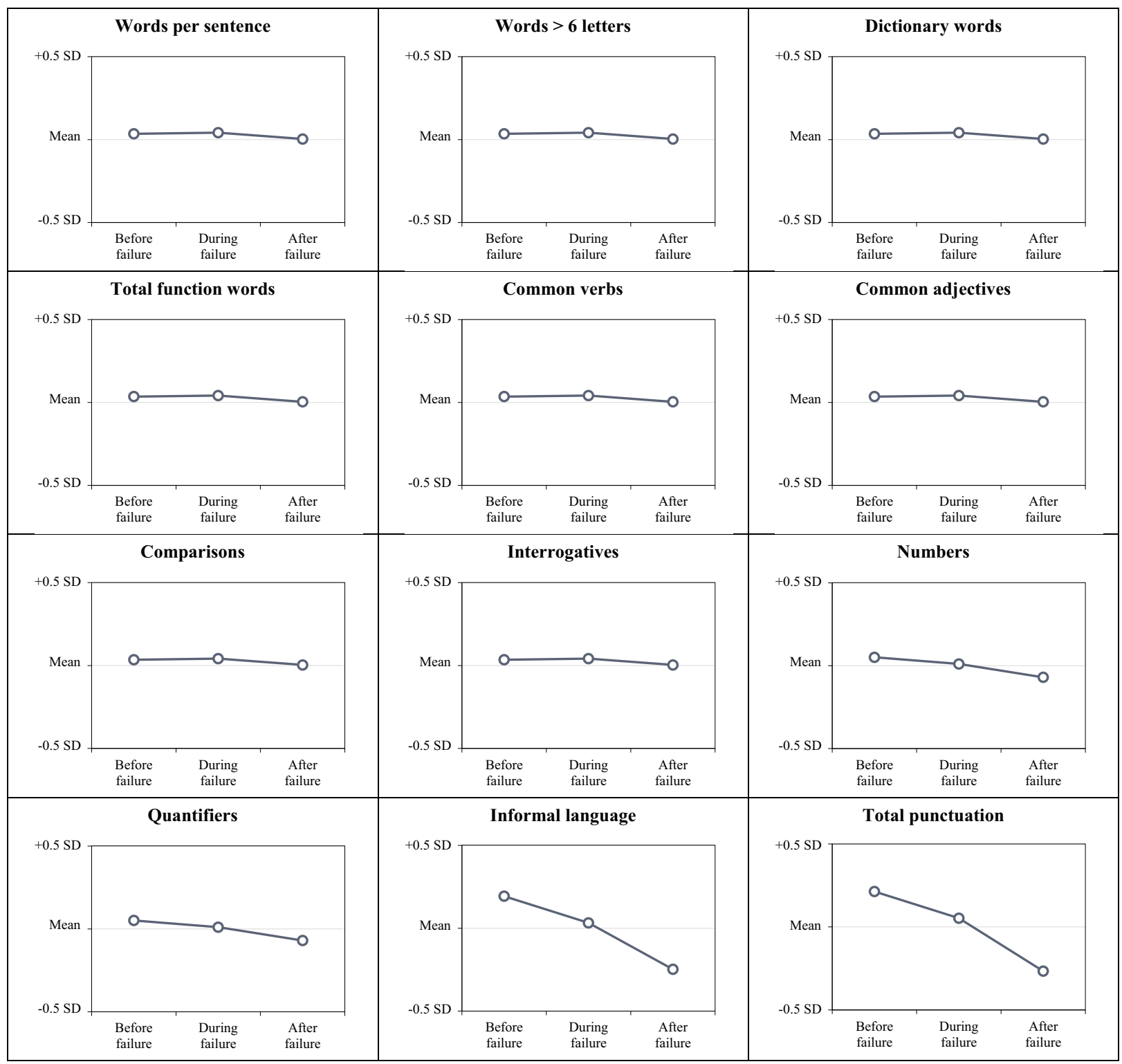

Fig. 1a. Mean values of the linguistic variables over the three periods. Notes: $\mathrm{N}=2,280$ observations (760 entrepreneurs with before, during, and after values each). The graphs are based on the mean values and standard deviations (SD) reported in Table 2.

$(\mathrm{p}=.00)$ during and after failure. The results also indicate that entrepreneurs use more words related to cognition $(\mathrm{p}=.00)$ but use fewer words referring to perceptions $(\mathrm{p}=.00)$, biology $(\mathrm{p}=.00)$, and relativity $(\mathrm{p}=.00)$ during and after failure. Regarding entrepreneurs' personal concerns, the results show that entrepreneurs talk more about money $(\mathrm{p}=.10)$ and death $(\mathrm{p}=.02)$ during and after failure, while they talk less about leisure $(\mathrm{p}=.00)$.

To further illustrate these differences across time, Fig. 1a and Fig. 1b graphically plot each variable's mean value over time. Since the variables are scaled differently, we standardize the figures using each variable's overall mean value and standard deviation. For example, Fig. 1b demonstrates marked differences across time for the analytical thinking and emotional tone variables. The figures also indicate that the effect of failure may not always be linear. For example, analytical thinking decreases from before failure to during failure and then increases from during failure to after failure. Despite this increase, the value after failure is lower than the initial value before failure. A possible interpretation of this dynamic is that entrepreneurs may be particularly unanalytic when experiencing failure but quickly recover from this downturn. 


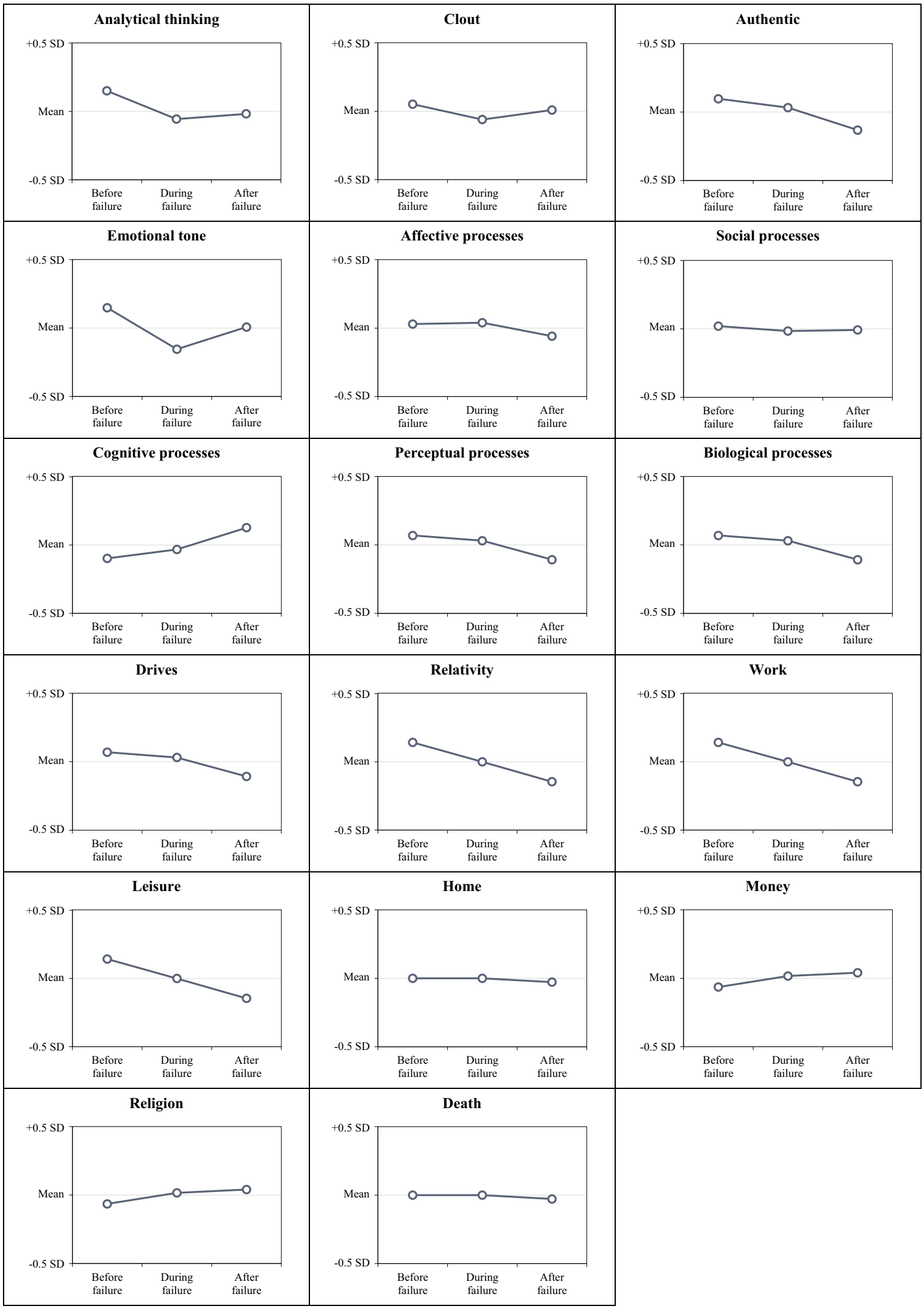


Fig. 1b. Mean values of the linguistic variables over the three periods. Notes: $\mathrm{N}=2,280$ observations (760 entrepreneurs with before, during, and after values each). The graphs are based on the mean values and standard deviations (SD) reported in Table 2.

\subsection{Multivariate regression analysis}

\subsubsection{Method: fixed effects panel regression}

Our analyses include longitudinal data from 760 entrepreneurs. Based on each entrepreneur's Tweets, we calculate a score for each LIWC variable before, during, and after failure. This process yields a balanced panel data set that comprises 2280 observations (760 entrepreneurs with three values each).

We use a linear panel regression with entrepreneur-level fixed effects as our main analysis. Using a fixed effects estimator enables us to control for all entrepreneur-level heterogeneity (e.g., unobserved variables, time-invariant variables) and to focus on variations within each entrepreneur. Since such intra-personal changes over time in response to failure are the focus of our investigation, a fixed effects (within) estimator is the most robust method of analysis to assess changes in entrepreneurs' digital identities.

Our models comprise all the LIWC variables as dependent variables. As independent variables, we include the dummy variables that differentiate the periods during failure and after failure (in reference to before failure). Additionally, all the models include the number of words analyzed in each period (word count (log.)) as a time-variant control variable. This way, we control for a potential association between the amount of text analyzed and the outcome variables. For the sake of brevity, Tables $2 \mathrm{a}$ and $2 \mathrm{~b}$ display only the coefficients and p-values of during failure and after failure. To further assess whether the coefficients of during failure and after failure differ in a statistically significant way, the tables also display the p-values obtained from a Wald test that compares these coefficients. The online appendix includes corresponding tables for all LIWC variables (Tables OA.II.2a and 2b).

\subsubsection{Description of the main results}

The results in Table 2a show significant differences across the majority of the linguistic variables regarding the periods before,

Table 2a

Multivariate regression results: linguistic variables.

\begin{tabular}{|c|c|c|c|c|c|c|}
\hline \multirow[b]{2}{*}{ Dependent variable } & \multicolumn{2}{|c|}{$\begin{array}{l}\text { (1) During failure (vs. before } \\
\text { failure) }\end{array}$} & \multicolumn{2}{|c|}{$\begin{array}{l}\text { (2) After failure (vs. before } \\
\text { failure) }\end{array}$} & \multirow[t]{2}{*}{$\begin{array}{l}\text { p-value (1) vs. } \\
\text { (2) }\end{array}$} & \multirow[t]{2}{*}{$\begin{array}{l}\text { Interpretation (in comparison to } \\
\text { before failure) }\end{array}$} \\
\hline & $\begin{array}{l}\text { Coef. } \\
\text { p-value }\end{array}$ & $\begin{array}{l}(\mathrm{SE}) \\
{[95 \% \mathrm{CI}]}\end{array}$ & $\begin{array}{l}\text { Coef. } \\
\text { p-value }\end{array}$ & $\begin{array}{l}\text { (SE) } \\
{[95 \% \mathrm{CI}]}\end{array}$ & & \\
\hline \multicolumn{7}{|c|}{ General language descriptors } \\
\hline Words per sentence & $\begin{array}{l}1.419 \\
0.006\end{array}$ & $\begin{array}{l}(0.516) \\
{[0.408,2.430]}\end{array}$ & $\begin{array}{l}0.663 \\
0.071\end{array}$ & $\begin{array}{l}(0.367) \\
{[-0.057,1.383]}\end{array}$ & 0.108 & Higher during failure \\
\hline Words $>6$ letters & $\begin{array}{l}-0.216 \\
0.327\end{array}$ & $\begin{array}{l}(0.220) \\
{[-0.647,0.215]}\end{array}$ & $\begin{array}{l}0.355 \\
0.023\end{array}$ & $\begin{array}{l}(0.157) \\
{[0.048,0.662]}\end{array}$ & 0.005 & Higher after failure \\
\hline Dictionary words & $\begin{array}{l}0.455 \\
0.142\end{array}$ & $\begin{array}{l}(0.310) \\
{[-0.153,1.064]}\end{array}$ & $\begin{array}{l}0.493 \\
0.026\end{array}$ & $\begin{array}{l}(0.221) \\
{[0.060,0.926]}\end{array}$ & 0.894 & Higher after failure \\
\hline \multicolumn{7}{|l|}{ Linguistic dimensions } \\
\hline Total function words & $\begin{array}{l}0.678 \\
0.011\end{array}$ & $\begin{array}{l}(0.265) \\
{[0.159,1.197]}\end{array}$ & $\begin{array}{l}1.100 \\
0.000\end{array}$ & $\begin{array}{l}(0.188) \\
{[0.731,1.470]}\end{array}$ & 0.080 & $\begin{array}{l}\text { Higher during failure, even higher } \\
\text { after failure }\end{array}$ \\
\hline Common verbs & $\begin{array}{l}0.083 \\
0.609\end{array}$ & $\begin{array}{l}(0.163) \\
{[-0.236,0.403]}\end{array}$ & $\begin{array}{l}-0.218 \\
0.060\end{array}$ & $\begin{array}{l}(0.116) \\
{[-0.446,0.009]}\end{array}$ & 0.042 & 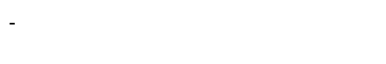 \\
\hline Common adjectives & $\begin{array}{l}0.141 \\
0.125\end{array}$ & $\begin{array}{l}(0.092) \\
{[-0.039,0.320]}\end{array}$ & $\begin{array}{l}0.042 \\
0.517\end{array}$ & $\begin{array}{l}(0.065) \\
{[-0.086,0.170]}\end{array}$ & 0.239 & - \\
\hline Comparisons & $\begin{array}{l}0.164 \\
0.006\end{array}$ & $\begin{array}{l}(0.059) \\
{[0.048,0.280]}\end{array}$ & $\begin{array}{l}0.208 \\
0.000\end{array}$ & $\begin{array}{l}(0.042) \\
{[0.125,0.290]}\end{array}$ & 0.417 & $\begin{array}{l}\text { Higher during failure, higher after } \\
\text { failure }\end{array}$ \\
\hline Interrogatives & $\begin{array}{l}0.099 \\
0.030\end{array}$ & $\begin{array}{l}(0.046) \\
{[0.009,0.189]}\end{array}$ & $\begin{array}{l}0.069 \\
0.035\end{array}$ & $\begin{array}{l}(0.033) \\
{[0.005,0.133]}\end{array}$ & 0.468 & $\begin{array}{l}\text { Higher during failure, higher after } \\
\text { failure }\end{array}$ \\
\hline Numbers & $\begin{array}{l}-0.073 \\
0.389\end{array}$ & $\begin{array}{l}(0.084) \\
{[-0.238,0.093]}\end{array}$ & $\begin{array}{l}-0.175 \\
0.004\end{array}$ & $\begin{array}{l}(0.060) \\
{[-0.293,-0.057]}\end{array}$ & 0.184 & Lower after failure \\
\hline Quantifiers & $\begin{array}{l}0.074 \\
0.159\end{array}$ & $\begin{array}{l}(0.052) \\
{[-0.029,0.177]}\end{array}$ & $\begin{array}{l}0.165 \\
0.000\end{array}$ & $\begin{array}{l}(0.037) \\
{[0.092,0.238]}\end{array}$ & 0.056 & Higher after failure \\
\hline Informal language & & & & & & \\
\hline Informal language & $\begin{array}{l}-0.137 \\
0.067\end{array}$ & $\begin{array}{l}(0.075) \\
{[-0.283,0.010]}\end{array}$ & $\begin{array}{l}-0.611 \\
0.000\end{array}$ & $\begin{array}{l}(0.053) \\
{[-0.715,-0.507]}\end{array}$ & 0.000 & Lower after failure \\
\hline $\begin{array}{l}\text { Punctuation } \\
\text { Total punctuation }\end{array}$ & -0.886 & $(0.358)$ & -3.492 & $(0.255)$ & 0.000 & Lower during failure, even lower after \\
\hline
\end{tabular}

Notes: This table displays the results of linear panel regressions with fixed effects at the entrepreneur-level. Each row refers to a separate regression analysis, in which the respective LIWC variable is used as the dependent variable. All models are based on 2280 observations (760 entrepreneurs with before, during, and after values each) and include 'word count (log.)' as a control variable. The penultimate column displays the results of a Wald test to determine whether the coefficients (1) and (2) differ in a statistically significant way. The full regression output for each variable is displayed in the online appendix. 
Table 2b

Multivariate regression results: psychological variables.

\begin{tabular}{|c|c|c|c|c|c|c|}
\hline \multirow[t]{2}{*}{ Dependent variable } & \multicolumn{2}{|c|}{ (1) During failure (vs. before failure) } & \multicolumn{2}{|c|}{ (2) After failure (vs. before failure) } & \multirow{2}{*}{$\begin{array}{l}\text { p-value (1) vs. } \\
\text { (2) }\end{array}$} & \multirow{2}{*}{$\begin{array}{l}\text { Interpretation (in comparison to before } \\
\text { failure) }\end{array}$} \\
\hline & $\begin{array}{l}\text { Coef. } \\
\text { p-value }\end{array}$ & $\begin{array}{l}(\mathrm{SE}) \\
{[95 \% \mathrm{CI}]}\end{array}$ & $\begin{array}{l}\text { Coef. } \\
\text { p-value }\end{array}$ & $\begin{array}{l}(\mathrm{SE}) \\
{[95 \% \mathrm{CI}]}\end{array}$ & & \\
\hline \multicolumn{7}{|l|}{ Summary variables } \\
\hline \multirow[t]{2}{*}{ Analytical thinking } & -2.257 & $(0.660)$ & -1.319 & $(0.470)$ & \multirow[t]{2}{*}{0.119} & \multirow{2}{*}{$\begin{array}{l}\text { Lower during failure, } \\
\text { lower after failure }\end{array}$} \\
\hline & 0.001 & {$[-3.550 ;-0.963]$} & 0.005 & {$[-2.240,-0.397]$} & & \\
\hline \multirow[t]{2}{*}{ Clout } & -0.401 & $(0.770)$ & -0.375 & $(0.548)$ & \multirow[t]{2}{*}{0.970} & \multirow[t]{2}{*}{-} \\
\hline & 0.602 & {$[-1.911,1.109]$} & 0.495 & {$[-1.450,0.701]$} & & \\
\hline \multirow[t]{2}{*}{ Authentic } & -3.913 & $(1.077)$ & -4.672 & $(0.767)$ & \multirow[t]{2}{*}{0.440} & \multirow{2}{*}{$\begin{array}{l}\text { Lower during failure, } \\
\text { lower after failure }\end{array}$} \\
\hline & 0.000 & {$[-6.026,-1.801]$} & 0.000 & {$[-6.176,-3.168]$} & & \\
\hline \multirow[t]{2}{*}{ Emotional tone } & -3.056 & $(1.172)$ & -2.309 & $(0.835)$ & \multirow[t]{2}{*}{0.485} & \multirow{2}{*}{$\begin{array}{l}\text { Lower during failure, } \\
\text { lower after failure }\end{array}$} \\
\hline & 0.009 & {$[-5.355,-0.757]$} & 0.006 & {$[-3.947,-0.672]$} & & \\
\hline \multicolumn{7}{|l|}{ Psychological processes } \\
\hline \multirow[t]{2}{*}{ Affective processes } & 0.068 & $(0.119)$ & -0.170 & $(0.085)$ & \multirow[t]{2}{*}{0.028} & \multirow[t]{2}{*}{ Lower after failure } \\
\hline & 0.566 & {$[-0.165,0.302]$} & 0.044 & {$[-0.337,-0.004]$} & & \\
\hline \multirow[t]{2}{*}{ Social processes } & 0.005 & $(0.147)$ & -0.055 & $(0.105)$ & \multirow[t]{2}{*}{0.654} & \multirow[t]{2}{*}{-} \\
\hline & 0.972 & {$[-0.283,0.294]$} & 0.601 & {$[-0.260,0.151]$} & & \\
\hline \multirow[t]{2}{*}{ Cognitive processes } & 0.502 & $(0.141)$ & 0.682 & $(0.101)$ & 0.163 & Higher during failure, \\
\hline & 0.000 & {$[0.225,0.779]$} & 0.000 & {$[0.485,0.879]$} & & higher after failure \\
\hline Perceptual processes & -0.034 & $(0.080)$ & -0.232 & $(0.057)$ & 0.007 & Lower after failure \\
\hline & 0.669 & {$[-0.191,0123]$} & 0.000 & {$[-0.343,-0.120]$} & & \\
\hline Biological processes & -0.100 & $(0.066)$ & -0.272 & $(0.047)$ & 0.004 & Lower after failure \\
\hline & 0.127 & {$[-0.229,0.029]$} & 0.000 & {$[-0.363,-0.180]$} & & \\
\hline Drives & 0.034 & $(0.130)$ & 0.125 & $(0.092)$ & 0.441 & - \\
\hline & 0.795 & {$[-0.221,0.289]$} & 0.176 & {$[-0.056,0.306]$} & & \\
\hline Relativity & -0.863 & $(0.169)$ & -0.907 & $(0.120)$ & 0.773 & Lower during failure, \\
\hline & 0.000 & {$[-1.195,-0.531]$} & 0.000 & {$[-1.144,-0.671]$} & & lower after failure \\
\hline Personal concerns & & & & & & \\
\hline Work & 0.076 & $(0.114)$ & 0.176 & $(0.081)$ & 0.338 & Higher after failure \\
\hline & 0.504 & {$[-0.148,0.300]$} & 0.030 & {$[0.017,0.336]$} & & \\
\hline Leisure & -0.171 & $(0.076)$ & -0.388 & $(0.054)$ & 0.002 & Lower during failure, \\
\hline & 0.024 & {$[-0.319,-0.023]$} & 0.000 & {$[-0.493,-0.282]$} & & even lower after failure \\
\hline Home & -0.045 & $(0.023)$ & -0.022 & $(0.017)$ & 0.265 & - \\
\hline & 0.053 & {$[-0.091,0.001]$} & 0.196 & {$[-0.054,0.011]$} & & \\
\hline Money & 0.106 & $(0.070)$ & 0.133 & $(0.050)$ & 0.680 & Higher after failure \\
\hline & 0.126 & {$[-0.030,0.243]$} & 0.008 & {$[0.035,0.230]$} & & \\
\hline Religion & 0.009 & $(0.017)$ & -0.004 & $(0.012)$ & 0.411 & - \\
\hline & 0.599 & {$[-0.024,0.041]$} & 0.752 & {$[-0.027,0.020]$} & & \\
\hline Death & 0.022 & $(0.018)$ & 0.043 & $(0.013)$ & 0.196 & Higher after failure \\
\hline & 0.243 & {$[-0.015,0.058]$} & 0.001 & {$[0.018,0.069]$} & & \\
\hline
\end{tabular}

Notes: This table displays the results of linear panel regressions with fixed effects at the entrepreneur-level. Each row refers to a separate regression analysis, in which the respective LIWC variable is used as the dependent variable. All models are based on 2280 observations (760 entrepreneurs with before, during, and after values each) and include 'word count (log.)' as a control variable. The penultimate column displays the results of a Wald test to determine whether the coefficients (1) and (2) differ in a statistically significant way. The full regression output for each variable is displayed in the online appendix.

during, and after failure. For example, words with more than six letters ( $\mathrm{p}_{\text {after }}=0.02$ ), dictionary words $\left(\mathrm{p}_{\mathrm{after}}=0.03\right.$ ), and quantifiers $\left(\mathrm{p}_{\mathrm{after}}=0.00\right)$ are higher after failure while words per sentence ( $\mathrm{p}_{\text {during }}=0.01$ ) is higher during failure. Additionally, the following variables are higher during failure and after failure: total function words ( $\mathrm{p}_{\text {during }}=0.01, \mathrm{p}_{\text {after }}=0.00$ ), comparisons ( $\mathrm{p}_{\text {during }}=0.01, \mathrm{p}_{\mathrm{after}}=0.00$ ), and interrogatives ( $\mathrm{p}_{\text {during }}=0.03, \mathrm{p}_{\mathrm{after}}=0.04$ ). For the total function words variable, the increase over time is particularly pronounced, as the variable further increases significantly from during failure to after failure ( $\mathrm{p}=.08)$. In contrast, entrepreneurs use fewer numbers $\left(\mathrm{p}_{\mathrm{after}}=0.00\right)$ and informal language $\left(\mathrm{p}_{\mathrm{after}}=.00\right)$ after failure. Additionally, they use less punctuation ( $\mathrm{p}_{\text {during }}=0.01, \mathrm{p}_{\mathrm{after}}=0.00$ ) during failure and after failure. This finding suggests that failure has a more immediate impact on punctuation than for the variables that only decrease in reference to the variables that are lower after failure but not during failure. The further decrease from during failure to after failure is statistically significant $(\mathrm{p}=.00$ ), which suggests a gradually decreasing effect.

Similarly, Table $2 \mathrm{~b}$ documents substantial differences in LIWC's psychological variables. In particular, the results indicate that entrepreneurs use fewer words referring to affect $\left(\mathrm{p}_{\mathrm{after}}=0.04\right)$, perceptions $\left(\mathrm{p}_{\mathrm{after}}=0.00\right)$, biology $\left(\mathrm{p}_{\mathrm{after}}=0.00\right)$, and work $\left(\mathrm{p}_{\text {after }}=0.03\right)$ after failure. Also, the results show a more immediate negative relation between failure and analytical thinking ( $\left.\mathrm{p}_{\text {during }}=0.00, \mathrm{p}_{\text {after }}=0.01\right)$, authenticity ( $\left.\mathrm{p}_{\text {during }}=0.00, \mathrm{p}_{\text {after }}=0.00\right)$, emotional tone ( $\left.\mathrm{p}_{\text {during }}=0.01, \mathrm{p}_{\text {after }}=0.01\right)$, relativity $\left(\mathrm{p}_{\text {during }}=0.00, \mathrm{p}_{\mathrm{after}}=0.00\right)$, and leisure ( $\left.\mathrm{p}_{\text {during }}=0.02, \mathrm{p}_{\mathrm{after}}=0.00\right)$. All these variables are significantly lower during failure and after failure. Further, leisure is significantly lower after failure than during failure $(\mathrm{p}=.00)$, indicating a gradual decline over time. In contrast, entrepreneurs talk significantly more about money $\left(\mathrm{p}_{\mathrm{after}}=0.01\right)$ and death $\left(\mathrm{p}_{\mathrm{after}}=0.00\right)$ after failure and use more words 


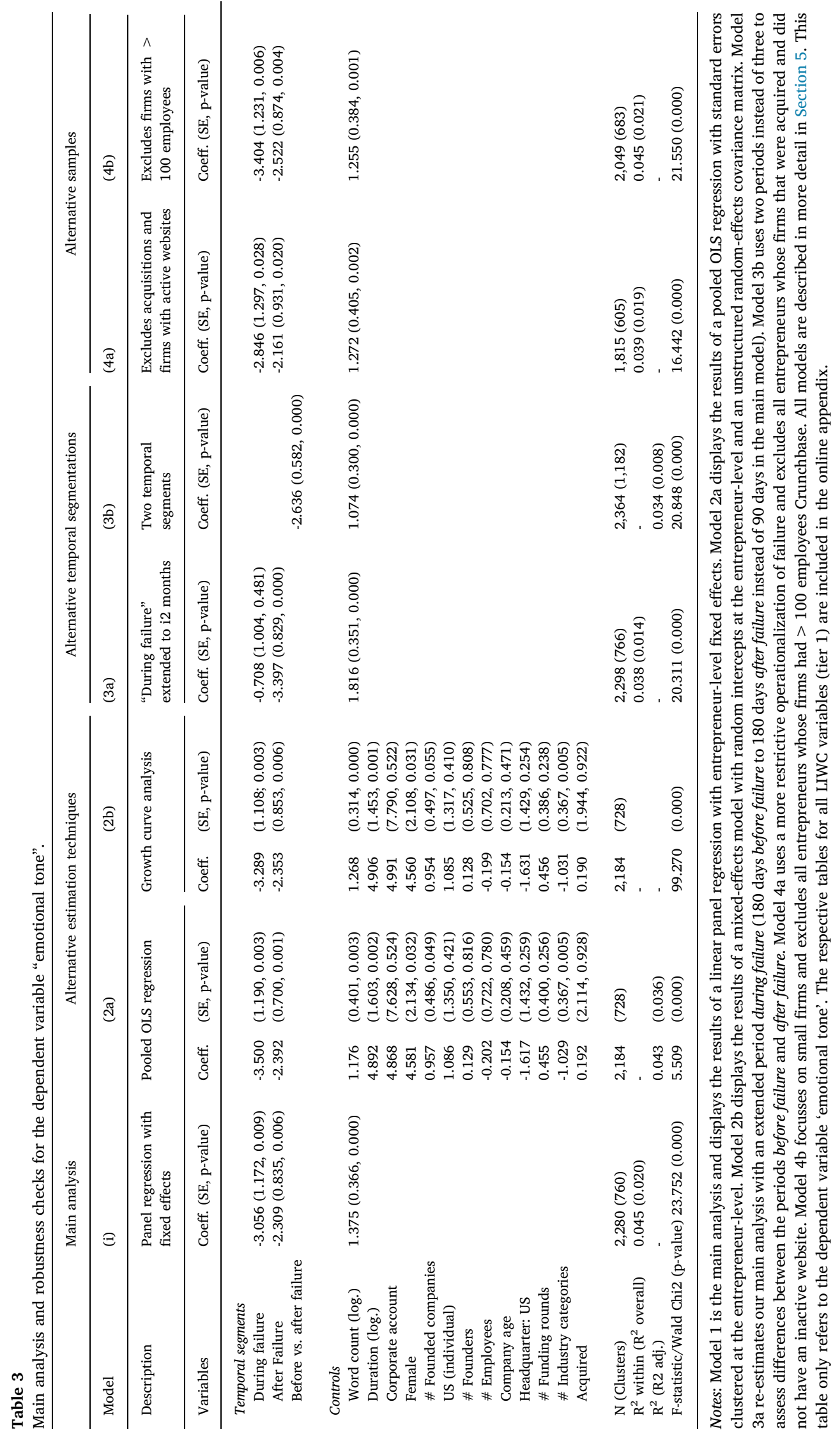


reflective of cognitive processes ( $\mathrm{p}_{\text {during }}=0.00, \mathrm{p}_{\mathrm{after}}=0.00$ ) during and after failure. Finally, our results indicate that the values for both analytical thinking and emotional tone are lower during failure and then increase after failure, suggesting a u-shaped relationship. However, the difference between the two coefficients is not statistically significant.

\subsection{Robustness checks and further analyses}

We perform multiple additional analyses to assess the robustness of our main results. We perform these robustness checks for all the LIWC variables (tier 1). Due to the breadth of the analyses, Table 3 only illustrates the results for one dependent variable (emotional tone). The full set of tables is included in our online appendix (Tables OA.I.1-29).

\subsubsection{Alternative estimation techniques}

5.3.1.1. Pooled OLS regression. In addition to the fixed effects estimator, we estimate a pooled OLS regression model with standard errors clustered at the entrepreneur-level. This specification allows the inclusion of time-invariant covariates, which enables additional insights into the determinants of entrepreneurs' digital identities. The control variables comprise Twitter characteristics, individual characteristics, and venture characteristics. The online appendix (Table OA.I.30) summarizes all variables, their definitions, data sources, and outlines descriptive statistics.

Model 2a of Table 3 shows that multiple control variables influence emotional tone. For example, female entrepreneurs have higher values in emotional tone than male entrepreneurs $(\mathrm{p}=.03)$. Additionally, a positive relationship exists between the number of founded companies and emotional tone $(\mathrm{p}=.05)$.

5.3.1.2. Growth curve analysis. In a further robustness check, we re-estimate our main model using growth curve analysis, which specializes in modeling changes over time. In contrast to the fixed effects estimator used in the main analysis, the growth effects model uses a maximum-likelihood estimator, quantifies the variability across entrepreneurs via the inclusion of random intercepts, and allows for the inclusion of time-invariant covariates.

Model 2b (Table 3) displays the results of such a mixed effects model with random intercepts at the entrepreneur-level and an unstructured random effects covariance matrix. The results are similar to the main results in terms of the magnitude and significance, emphasizing their robustness.

\subsubsection{Alternative temporal segmentations}

5.3.2.1. Extension of during failure period. Our main analysis operationalizes the effect of failure via a set of dummy variables that distinguish three periods of time. The period during failure captures the period between 90 days before failure and 90 days after failure. Prior research highlights that failure can be a lengthy process, especially when considering the recovery period after a failure (e.g., Cope, 2011; Singh et al., 2007; Ucbasaran et al., 2013). To explore the results using a longer difference between before and after failure, we thus extend the period during failure to 180 days before failure and 180 days after failure.

The results displayed in Model 3a (Table 3) emphasize the robustness of the main results with regard to the difference between before and after failure. However, the effect of during failure is weaker $(\mathrm{p}=.48$ ), indicating that the negative effect identified in the main analysis is less pronounced when the period is extended. In turn, this indicates that the negative influence of failure is more pronounced in the short period surrounding the date of business closure, speaking to the measurement used in our main analysis.

5.3.2.2. Two temporal segments (before vs. after) instead of three (before, during, and after). As a further robustness check, we use a more general temporal segmentation in Model 3b (Table 3). Here, we consider only two time periods that distinguish Tweets issued before failure from those issued after failure. The differences between the before and after values are captured by the dummy variable before vs. after failure.

The results emphasize the robustness of our main analysis and document that significant differences exist between the before and after failure values of emotional tone $(\mathrm{p}=.00)$.

\subsubsection{Alternative samples}

5.3.3.1. More restrictive operationalization of entrepreneurial failure. While the discontinuation of operations is a commonly used proxy for failure (Josefy et al., 2017), prior studies highlight the need for greater precision when conceptualizing failure (e.g., Balcaen et al., 2012; Wennberg et al., 2010). A case in point is the treatment of acquisitions. While prior research often considers acquisitions as failures, acquisitions can also indicate success, especially for entrepreneurial ventures and the entrepreneur (e.g., Henkel et al., 2014; Josefy et al., 2017; Wennberg et al., 2010).

We thus perform a robustness check in which we use a more restrictive operationalization of failure. First, Crunchbase enables us to identify ventures that were acquired. We exclude these ventures since their classification as failed is not always straightforward $(N=110)$. Second, we manually researched all 760 observations to determine whether the venture's website is still active (as of December 1st, 2019). We were able to identify the websites of 742 companies, of which 79 were still active. This includes ventures that were acquired and now redirect their websites to the company that acquired them. In total, 663 of 742 ventures did not have an active website anymore.

We restrict our sample to entrepreneurs whose ventures were not acquired and do not currently have an active website. This reduces our sample from 760 entrepreneurs to 605. The results are displayed in Model 4a (Table 3). Despite the reduced sample size, the main effects are similar in magnitude and significance. 
5.3.3.2. Focus on smaller ventures. To enable accurate inferences, research on digital identities implicitly assumes that the data used (i.e., Tweets) actually stem from the individuals under investigation. However, entrepreneurs' Twitter accounts could be managed professionally by a company's social media team or a marketing agency (e.g., Obschonka and Fisch, 2018). We argue that the professional management of an entrepreneur's social media account by a third party is more likely to occur in larger companies. Larger ventures are more likely to have the resources for a dedicated social media team or for hiring a professional marketing agency. Additionally, large companies may face higher pressures for conforming behavior and may thus be more likely to alter their communication in a more professionalized way.

Thus, we re-estimate our main analysis using a subsample of smaller companies. Specifically, we use the information on company size included in Crunchbase and remove all companies with $>100$ employees at closure. This reduces our sample from 760 to 685 entrepreneurs. The results are displayed in Model $4 \mathrm{~b}$ (Table 3) and do not indicate substantial differences between smaller and larger companies.

\subsubsection{Assessing a potential selection bias}

Our findings refer to the group of entrepreneurs who use Twitter and continue to use Twitter when experiencing failure. In further analyses, we transparently document and assess a potential selection bias that could limit the generalizability of our findings.

First, we compare (1) the group of entrepreneurs who experienced failure and do not have a Twitter account with (2) the group of entrepreneurs who experienced failure and have a Twitter account. Within the group of entrepreneurs who have Twitter accounts, we then compare those entrepreneurs who (3) are not included in our final sample with the entrepreneurs who (4) are included in our final sample. The detailed comparison is displayed in the online appendix (Table OA.I.31). For example, the results indicate that entrepreneurs in our final sample are more often from the US $(\mathrm{p}=.00)$ and have received more rounds of funding ( $\mathrm{p}=.01)$. While several significant differences emerge, these differences are generally small.

Second, another potential selection bias concerns dropout due to failure (i.e., individuals who used Twitter before failure but then stopped using Twitter during failure). In total, our sample comprises 1457 entrepreneurs with sufficient Twitter information before failure, which is reduced to 795 (54.6\%) in the period during failure, and then further decreases to 760 (52.2\%) after failure (final sample). Hence, we compare the entrepreneurs who stopped using Twitter after the first period to the entrepreneurs who continued to use Twitter. The results (online appendix, Table OA.I.32) show, for example, that the entrepreneurs who continue to use Twitter during failure score lower in terms of analytical thinking $(\mathrm{p}=.00)$, clout $(\mathrm{p}=.00)$, and work $(\mathrm{p}=.00)$ while they score higher in affective processes $(\mathrm{p}=.04)$. This suggests that more affective persons may be more sensitive to failure and may thus be more likely to stop using Twitter. This could potentially contribute to explaining the nonsignificant findings in our main analyses. In contrast, no significant differences emerge with regard to many of our main results, such as authenticity, emotional tone, or death. This indicates that the results for these variables should be free of this bias.

\section{Discussion and conclusion}

\subsection{Discussion and interpretation of the main results}

The results of our explorative research indicate that the financial, social, and psychological consequences of failure are reflected in entrepreneurs' digital identities and language on Twitter. We summarize and interpret our findings in Table 4. In line with this study's exploratory nature, we try to provide a broad overview and interpretation of the results instead of focusing on selected constructs.

\subsubsection{Financial consequences of failure}

Failure is associated with a reduction in personal income and an accumulation of debt. We find that entrepreneurs use more words related to work and money after failure, suggesting an increase in the importance of these personal concerns. Similarly, entrepreneurs talk less about leisure activities. These findings are in line with prior research (e.g., Cope, 2011; Singh et al., 2007), highlighting the financial distress resulting from entrepreneurial failure. Simultaneously, these results could indicate that entrepreneurs often need to seek new employment opportunities after experiencing failure (Cope, 2011; Ucbasaran et al., 2013).

\subsubsection{Social consequences of failure}

Prior research points to the breakdown of marriages, the distancing from family and friends, and substantial reputational losses (e.g., Cope, 2011; Singh et al., 2007). Supporting this notion of social consequences, our results indicate that entrepreneurs talk less about friends and leisure time, indicating less interest in social contact and activities. Additionally, entrepreneurs score lower in terms of affectiveness after failure, which could be damaging to social relations. These results indicate that entrepreneurs indeed seem to experience a reduction in their social standing after failure. This finding is in line with prior research that describes a devaluation of the entrepreneur's social identity after failure (e.g., Shepherd and Haynie, 2011; Singh et al., 2015).

\subsubsection{Psychological consequences of failure}

Concerning the negative psychological consequences of failure, we find that entrepreneurs' emotional tone tends to decrease after failure. Similarly, entrepreneurs become less affective. Both findings could indicate a self-distancing reaction by entrepreneurs, which is frequently outlined in prior research (e.g., Cope, 2011; Singh et al., 2015). The finding could also reflect that entrepreneurs assign blame for the failure to themselves, becoming more apathetic as a result. Further speaking to this point, entrepreneurs become less 
analytic, which could indicate resignation or a sense of helplessness. This is in line with prior research that indicates that failure can lead to psychological distress and a sense of helplessness, which hinder future task performance (e.g., Jenkins et al., 2014; Ng and Jenkins, 2018; Shepherd, 2003). Our findings also indicate that entrepreneurs are less future-oriented after failure, potentially indicating a fear of the unknown future. Finally, we find that entrepreneurs use more words associated with death after experiencing failure; this is in line with the literature on grief (e.g., Shepherd, 2003; Shepherd et al., 2009), which acknowledges that the death of a venture can provoke reactions similar to the grief experienced when losing a family member.

Regarding the positive psychological consequences of failure, we find that entrepreneurs use more words related to cognitive processes post-failure. Potentially, this indicates that entrepreneurs become more reflective and causal. This is in line with the notion that entrepreneurial failure provides the possibility for individual learning and growth to occur (e.g., Cope, 2011; Shepherd, 2003; Shepherd et al., 2009). Finally, prior research indicates that failure can also lead to positive motivational effects (e.g., Ucbasaran et al., 2013). Our results show that entrepreneurs become more achievement-driven. We also find an increased power-drive and risktaking propensity among entrepreneurs after failure, indicating increased self-assurance.

\subsection{Contributions and implications}

\subsubsection{Contributions to entrepreneurship research}

We contribute to entrepreneurship research in two main ways. First, we extend prior research on entrepreneurs' digital identities (e.g., Fischer and Reuber, 2011; Obschonka et al., 2017; Smith et al., 2017). So far, previous entrepreneurship research has assessed digital identities in the context of communication and networking strategies (e.g., Fischer and Reuber, 2011; Smith and Smith, 2019) and linked them to measures of entrepreneurial behavior, financing, and success (e.g., Block et al., 2019; Obschonka et al., 2017; Winkler et al., 2020). While these studies primarily focus on cross-sectional differences between entrepreneurs, we know little about whether and how entrepreneur's digital identities change over time and, in particular, how they are affected by "offline" businessrelated events such as failure. We address these questions and document that failure does indeed affect entrepreneurs' digital identities. Additionally, we capture entrepreneurs' digital identities in a nuanced way via a range of linguistic and psychological dimensions. Using such a fine-grained measure allows us to analyze the impact of failure on different components of entrepreneurs' identities. We find evidence for identity dimensions that are higher or lower after failure, while other dimensions are not affected by failure at all. This assessment highlights the complexity and multidimensional character of an entrepreneur's digital identity and underlines the need for a scrutinization of the different identity components in future research. A better understanding of entrepreneurs' digital identities is also important because entrepreneurs use digital identies and impression management to interact with their stakeholders, which influences venture success (e.g., Nambisan, 2017; Obschonka et al., 2017; Smith et al., 2017). Thus, our findings are also related to studies on entrepreneurs' impression management after failure (e.g., Byrne and Shepherd, 2015; Kibler et al., 2017). Our longitudinal empirical approach allows a comparison of digital identies and impression management before and after failure. The investigation of impression management strategies of entrepreneurs also connects our findings to general management research, in which impression management is a recurring theme (e.g., Bolino et al., 2008).

Second, we contribute to the literature on entrepreneurial failure (e.g., Cope, 2011; Jenkins et al., 2014; Shepherd, 2003; Ucbasaran et al., 2013). We extend this body of research by documenting failure's profound, identity-changing consequences using a

Table 4

Summary of the main results.

\begin{tabular}{|c|c|c|}
\hline Consequence of failure & LIWC variables & Possible interpretation \\
\hline \multirow[t]{2}{*}{$\begin{array}{l}\text { Financial consequences } \\
\text { (negative) }\end{array}$} & $\begin{array}{l}\text { Concern: Work }(+) \\
\text { Concern: Leisure }(-)\end{array}$ & Seek new employment \\
\hline & Concern: Money $(+)$ & Financial distress \\
\hline \multirow{3}{*}{$\begin{array}{l}\text { Social consequences } \\
\text { (negative) }\end{array}$} & Friends $(-)$ & Loss of social contacts \\
\hline & Concern: Leisure $(-)$ & Less social activity \\
\hline & Third person plural $(+)$ & Blaming others \\
\hline \multirow{9}{*}{$\begin{array}{l}\text { Psychological consequences } \\
\text { (negative) }\end{array}$} & Emotional tone $(-)$ & Self-distancing, psychological distress \\
\hline & Affective processes $(-)$ & \\
\hline & Perceptual processes $(-)$ & \\
\hline & Biological processes $(-)$ & \\
\hline & Analytical thinking $(-)$ & Resignation, helplessness \\
\hline & Positive emotion $(-)$ & \\
\hline & Future focus $(-)$ & Fear of unknown \\
\hline & Concern: Death $(+)$ & Loss of venture \\
\hline & Assent $(-)$ & Less agreeable \\
\hline \multirow{4}{*}{$\begin{array}{l}\text { Psychological consequences } \\
\text { (positive) }\end{array}$} & Cognitive processes $(+)$ & More reflected \\
\hline & Achievement driven $(+)$ & Self-assurance \\
\hline & Power driven $(+)$ & \\
\hline & Risk (+) & \\
\hline
\end{tabular}

Notes: Tier 1 constructs are highlighted in bold. 
quantitative assessment based on longitudinal data. Our exploratory analyses provide a robust analysis of intra-individual differences across time while controlling for unobserved heterogeneity and inter-individual differences between entrepreneurs. Importantly, this approach enables insights into how entrepreneurs' digital identities respond to failure over different periods when experiencing failure. Specifically, we show that some dimensions of digital identity respond more quickly to failure than others. For example, we find that emotional tone decreases during failure, while affective processes decrease only after failure. Even though both variables are related, they appear to develop differently over time in response to failure. Knowing how the different aspects of entrepreneurs' digital identities respond to failure over time enables future research to develop a better understanding of failure as a process (e.g., Ucbasaran et al., 2013). This also includes the assessment of nonlinear u-shaped relationships that may exist for some variables. Overall, these findings highlight the importance of conceptualizing failure as a process instead of a singular event in future research (e.g., Cope, 2011; Ucbasaran et al., 2013).

\subsubsection{Implications: using Twitter data in future entrepreneurship research}

In addition to our main contributions, our empirical approach opens various avenues for future research in the domains of entrepreneurial failure, entrepreneurship in general, and entrepreneurs' digital identities.

Within the domain of entrepreneurial failure, a substream of research deals with resilience, grief, and recovery strategies after failure (e.g., Mandl et al., 2016; Shepherd, 2009; Ucbasaran et al., 2013). Using an empirical approach based on Twitter data would enable, for example, a detailed assessment of whether and how individuals recover from business failure. Specifically, research on entrepreneurs' grief recovery suggests that three types of recovery exist: immediate recovery, recovery after an extended period, and no recovery (e.g., Shepherd, 2003; Shepherd, 2009). Future studies could use Twitter data to assess the prominence of the different recovery strategies and to assess the relationship between these recovery strategies and subsequent entrepreneurship and occupational outcomes (e.g., restarting a venture, wage employment, unemployment).

Additionally, fruitful paths for future research exist in the more general entrepreneurship domain. Future studies can use a similar empirical setting to analyze how other entrepreneurship events than failure trigger changes in entrepreneurs' digital identities. To the extent that entrepreneurs or their stakeholders use Twitter and leave digital footprints, future research could analyze how the arrival of a venture capitalist (VC) as an investor changes an entrepreneur's communication and the professionalization of his or her venture as well as his or her psychological and emotional status. In a similar setting, one could analyze the emotional and motivational consequences of an IPO or another form of (positive) exit for the entrepreneurs and top managers involved (e.g., Balcaen et al., 2012; Henkel et al., 2014; Wennberg et al., 2010).

Finally, avenues for future research exist with regard to entrepreneurs' digital identities (e.g., Obschonka et al., 2017; Smith et al., 2017). Since social media is an important communication channel for entrepreneurs, knowledge on how entrepreneurs' digital identities change over time is a fruitful area of research, especially when considering that entrepreneurs' online self-representations will become even more critical in the future (e.g., Nambisan, 2017; Smith et al., 2017). Twitter is particularly useful for broadcasting information to a broad public audience in a quick, disintermediated way (e.g., Fischer and Reuber, 2011; Smith et al., 2017). Because of Twitter's immediate and quick nature, Tweets may also be a rather unreflective and authentic data source (e.g., Lee et al., 2017; Obschonka et al., 2017). While this authenticity is vital to capture the actual effect of failure on digital identities, the immediate and potentially unreflective nature of Tweets may produce statements that are more extreme and could overstate specific identity components (e.g., emotional behavior). Hence, a comparison of our Twitter-based results to results derived from text posted to other social networks (e.g., Facebook, LinkedIn) or other digital outlets (e.g., blogs, articles) is intriguing. The results of such a comparison would provide more context to our findings and would enable insights into whether entrepreneurs construct different digital identities across different digital platforms.

\subsection{Limitations}

First, we consider three periods (i.e., before, during, and after failure) when modeling the effects of failure over time. While our approach captures the dynamics of failure as a process and is superior to conceptualizing failure as a singular point in time, our measure is still relatively crude. For example, a more detailed analysis that considers changes in entrepreneurs' language every week might enable more nuanced insights into the ups and downs failure incurs. While technically possible, data restrictions prohibit such a fine-grained analysis, mainly because a minimum amount of Twitter data is required for every period under investigation.

Second, LIWC is a dictionary-based approach of language analysis that assesses how frequently individuals use a predefined set of words. While such closed-vocabulary approaches are popular in research, they are sensitive to the dictionary used and can only provide basic information on the language used by individuals. Recent studies employ more advanced open-vocabulary approaches (e.g., Park et al., 2015). Open-vocabulary approaches do not rely on predefined dictionaries and can provide more fine-grained linguistic insights. For example, such approaches are able to capture irony, neologisms, and contextual dimensions. These approaches frequently draw on machine learning techniques, such as neural networks or support-vector machines (e.g., Park et al., 2015; Schwartz et al., 2013). The use of such advanced methods of language analysis to revisit and extend our findings is a natural avenue for future research.

Third, we use the discontinuation of operations as a proxy for failure. In a robustness check, we use a more restrictive operationalization and further exclude those ventures that were acquired and those that still had active websites. Nevertheless, it is difficult to ascertain whether all of the ventures in our sample did indeed fail. To address this issue, we performed a manual web search for all 760 entrepreneurs and their respective ventures to identify information on the respective business closures, such as newspaper articles, blog posts, or posts on social media. We were able to identify such information for 231 of the 760 observations 
(30.4\%). Out of the 231 observations, 33 referred to ventures that were acquired. For 182 of the remaining 198 ventures (91.9\%), we were able to identify information that stated that the venture did indeed fail. Based on this manual search, we have high confidence that the vast majority of our entrepreneurs experienced failure.

Fourth, while our approach of using longitudinal data from Twitter is of comparatively high internal validity, limitations exist regarding external validity. Specifically, our results refer to the subgroup of entrepreneurs who use Twitter and continue to use Twitter when experiencing failure. A potential selection bias exists since entrepreneurs who use Twitter differ from entrepreneurs who are not on Twitter. While the differences outlined in Section 5.3.4 are not extreme and should not bias our main results to a large extent, they limit the generalizability of our results.

Relatedly, we study the effect of failure on entrepreneurs' digital identities. While it is tempting to make inferences about how failure affects entrepreneurs' actual (offline) identities based on our results, entrepreneurs' digital identities and their actual identities may not fully overlap. For example, entrepreneurs might use their Twitter accounts strategically and engage in impression management for marketing purposes or to acquire financing (e.g., Parhankangas and Ehrlich, 2014). Alternatively, entrepreneurs could lie or spread misinformation (e.g., Stephens-Davidowitz and Pabon, 2017). Notwithstanding this limitation, the digital identity that entrepreneurs create is an important construct that shapes how these individuals interact with stakeholders and is linked to venture success (e.g., Nambisan, 2017; Obschonka and Fisch, 2017; Smith et al., 2017).

\subsection{Conclusion}

Entrepreneurial failure is associated with financial, social, and psychological consequences for entrepreneurs. We apply a computerized text analysis to entrepreneurs' Tweets to capture and quantify these individual consequences of failure. Based on a sample of 760 entrepreneurs who experienced failure, we find that entrepreneurs' language on Twitter reflects the financial, social, and psychological consequences of failure. This suggests that entrepreneurs' digital identities can change in response to failure. Also, our results highlight that the consequences of entrepreneurial failure can be negative and positive.

Our nuanced assessment provides insights into the multidimensional character of an entrepreneur's digital identity. We also document failure's critical, identity-changing consequences for entrepreneurs using a quantitative assessment based on longitudinal data. As such, our study highlights the complexity of entrepreneurs' digital identities and the diversity of the consequences of failure. Finally, we underline the importance of conceptualizing failure as a process and we provide a detailed account of the potential of analyzing Twitter data for future entrepreneurship research.

\section{CRediT authorship contribution statement}

Christian Fisch: Conceptualization, Methodology, Investigation, Formal analysis, Data curation, Writing - original draft, Writing - review \& editing. Jörn H. Block: Conceptualization, Methodology, Writing - original draft, Writing - review \& editing.

\section{Acknowledgements}

We gratefully acknowledge the capable research assistance provided by Pascal Klos. Also, we thank Andreas Kuckertz, participants of the 2018 ACE Bootcamp in Brisbane (Australia), the 2019 TIE conference in Darmstadt (Germany), and the 2019 G-Forum in Vienna (Austria) for helpful comments on earlier versions of the manuscript.

\section{References}

Arora, A., Nandkumar, A., 2011. Cash-out or flameout! Opportunity cost and entrepreneurial strategy: theory, and evidence from the information security industry. Manag. Sci. 57 (10), 1844-1860.

Balcaen, S., Manigart, S., Buyze, J., Ooghe, H., 2012. Firm exit after distress: differentiating between bankruptcy, voluntary liquidation and M\&A. Small Bus. Econ. 39 (4), 949-975.

Birkinshaw, J., Haas, M., 2016. Increase your return to failure. Retrieved from. https://hbr.org/2016/05/increase-your-return-on-failure, Accessed date: 26 February 2020.

Block, J.H., Fisch, C., Obschonka, M., Sandner, P.G., 2019. A personality perspective on business angel syndication. J. Bank. Financ. 100, 306-327.

Bolino, M.C., Kacmar, K.M., Turnley, W.H., Gilstrap, J.B., 2008. A multi-level review of impression management motives and behaviors. J. Manag. 34 (6), 1080-1109.

Boyd, R.L., Pasca, P., Conroy-Beam, D., 2019. You're only Jung once: building generalized motivational systems theories using contemporary research on language. Psychol. Inq. 30 (2), 93-98.

Byrne, O., Shepherd, D.A., 2015. Different strokes for different folks: entrepreneurial narratives of emotion, cognition, and making sense of business failure. Entrepreneurship Theory and Practice 39 (2), 375-405.

Cardon, M.S., McGrath, R.G., 1999. When the going gets tough... Toward a psychology of entrepreneurial failure and re-motivation. Frontiers of Entrepreneurship Research 29 (4), 58-72.

Cardon, M.S., Zietsma, C., Saparito, P., Matherne, B.P., Davis, C., 2005. A tale of passion: new insights into entrepreneurship from a parenthood metaphor. Journal of BusinessVenturing 20 (1), 23-45.

Cardon, M.S., Wincent, J., Singh, J., Drnovsek, M., 2009. The nature and experience of entrepreneurial passion. Acad. Manag. Rev. 34 (3), $511-532$.

Cardon, M.S., Stevens, C.E., Potter, D.R., 2011. Misfortunes or mistakes? Cultural sensemaking of entrepreneurial failure. J. Bus. Ventur. 26 (1), 79-92.

Chen, L., Gong, T., Kosinski, M., Stillwell, D., Davidson, R.L., 2017. Building a profile of subjective well-being for social media users. PLoS One 12 (11), e0187278.

Cope, J., 2011. Entrepreneurial learning from failure: an interpretative phenomenological analysis. J. Bus. Ventur. 26 (6), $604-623$.

Crunchbase, 2019. The Crunchbase data difference. Retrieved from. https://about.crunchbase.com/products/the-crunchbase-difference, Accessed date: 9 December 2019.

Fisch, C., 2019. Initial coin offerings (ICOs) to finance new ventures. J. Bus. Ventur. 34 (1), 1-22.

Fischer, E., Reuber, A.R., 2011. Social interaction via new social media: (how) can interactions on Twitter affect effectual thinking and behavior? J. Bus. Ventur. 26 (1), 
$1-18$.

Fischer, E., Reuber, A.R., 2014. Online entrepreneurial communication: mitigating uncertainty and increasing differentiation via Twitter. J. Bus. Ventur. 29 (4), 565-583.

Gosling, S.D., Augustine, A.A., Vazire, S., Holtzman, N., Gaddis, S., 2011. Manifestations of personality in online social networks: self-reported Facebook-related behaviors and observable profile information. Cyberpsychol. Behav. Soc. Netw. 14 (9), 483-488.

Henkel, J., Rønde, T., Wagner, M., 2014. And the winner is - acquired. Entrepreneurship as a contest yielding radical innovations. Res. Policy 44 (2), 295-310.

Homburg, C., Hahn, A., Bornemann, T., Sandner, P., 2014. The role of chief marketing officers for venture capital funding: endowing new ventures with marketing legitimacy. J. Mark. Res. 51 (5), 625-644.

Jain, S., George, G., Maltarich, M., 2009. Academics or entrepreneurs? Investigating role identity modification of university scientists involved in commercialization activity. Res. Policy 38 (6), 922-935.

Jenkins, A.S., Wiklund, J., Brundin, E., 2014. Individual responses to firm failure: appraisals, grief, and the influence of prior failure experience. J. Bus. Ventur. 29 (1), $17-33$.

Josefy, M.A., Harrison, J.S., Sirmon, D.G., Carnes, C., 2017. Living and dying: synthesizing the literature on firm survival and failure across stages of development. Acad. Manag. Ann. 11 (2), 770-799.

Kibler, E., Mandl, C., Kautonen, T., Berger, E.S., 2017. Attributes of legitimate venture failure impressions. J. Bus. Ventur. 32 (2), 145-161.

Kosinski, M., Stillwell, D., Graepel, T., 2013. Private traits and attributes are predictable from digital records of human behavior. Proc. Natl. Acad. Sci. 110 (15), $5802-5805$.

Lee, S.H., Yamakawa, Y., Peng, M.W., Barney, J.B., 2011. How do bankruptcy laws affect entrepreneurship development around the world? J. Bus. Ventur. 26 (5), 505-520.

Lee, J.M., Hwang, B.H., Chen, H., 2017. Are founder CEOs more overconfident than professional CEOs? Evidence from S\&P 1500 companies. Strateg. Manag. J. 38 (3), $751-769$.

Mandl, C., Berger, E.S., Kuckertz, A., 2016. Do you plead guilty? Exploring entrepreneurs' sensemaking-behavior link after business failure. J. Bus. Ventur. Insights 5, 9-13.

Nadkarni, S., Chen, J., 2014. Bridging yesterday, today, and tomorrow: CEO temporal focus, environmental dynamism, and rate of new product introduction. Acad. Manag. J. 57 (6), 1810-1833.

Nambisan, S., 2017. Digital entrepreneurship: toward a digital technology perspective of entrepreneurship. Entrepreneurship Theory and Practice 41 (6), $1029-1055$.

Ng, L., Jenkins, A.S., 2018. Motivated but not starting: how fear of failure impacts entrepreneurial intentions. Small Enterp. Res. 25 (2), $152-167$.

Obschonka, M., Fisch, C., 2018. Entrepreneurial personalities in political leadership. Small Bus. Econ. 50 (4), 851-869.

Obschonka, M., Fisch, C., Boyd, R., 2017. Using digital footprints in entrepreneurship research: a Twitter-based personality analysis of superstar entrepreneurs and managers. J. Bus. Ventur. Insights 8, 13-23.

Paik, Y., 2014. Serial entrepreneurs and venture survival: evidence from U.S. Venture-capital-financed semiconductor firms. Strateg. Entrep. J. 8 (3), 254-268.

Parhankangas, A., Ehrlich, M., 2014. How entrepreneurs seduce business angels: an impression management approach. J. Bus. Ventur. 29 (4), 543-564.

Parhankangas, A., Renko, M., 2017. Linguistic style and crowdfunding success among social and commercial entrepreneurs. J. Bus. Ventur. 32 (2), 215-236.

Park, G., Schwartz, H.A., Eichstaedt, J.C., Kern, M.L., Kosinski, M., Stillwell, D.J., Ungar, L.H., Seligman, M.E., 2015. Automatic personality assessment through social media language. J. Pers. Soc. Psychol. 108 (6), 934-952.

Peng, M.W., Yamakawa, Y., Lee, S.H., 2010. Bankruptcy laws and entrepreneur-friendliness. Entrepreneurship Theory and Practice 34 (3), 517-530.

Pennebaker, J.W., Boyd, R.L., Jordan, K., Blackburn, K., 2015. The Development and Psychometric Properties of LIWC2015.

Schwartz, H.A., Eichstaedt, J.C., Kern, M.L., Dziurzynski, L., Ramones, S.M., Agrawal, M., Shah, A., Kosinski, M., Stillwell, D., Seligman, M.E., Ungar, L.H., 2013 Personality, gender, and age in the language of social media: the open-vocabulary approach. PLoS One 8 (9), e73791.

Shepherd, D.A., 2003. Learning from business failure: propositions of grief recovery for the self-employed. Acad. Manag. Rev. 28 (2), 318-328.

Shepherd, D.A., 2009. Birds of a feather don't always flock together: identity management in entrepreneurship. J. Bus. Ventur. 24 (4), 316-337.

Shepherd, D.A., Haynie, J.M., 2009. Birds of a feather don’t always flock together: identity management in entrepreneurship. J. Bus. Ventur. 24 (4), $316-337$.

Shepherd, D.A., Haynie, J.M., 2011. Venture failure, stigma, and impression management: a self-verification, self-determination view. Strateg. Entrep. J. 5 (2), 178-197.

Shepherd, D.A., Wiklund, J., Haynie, J.M., 2009. Moving forward: balancing the financial and emotional costs of business failure. J. Bus. Ventur. 24 (2), $134-148$. Simmons, S.A., Wiklund, J., Levie, J., 2014. Stigma and business failure: implications for entrepreneurs' career choices. Small Bus. Econ. 42 (3), $485-505$.

Singh, S., Corner, P., Pavlovich, K., 2007. Coping with entrepreneurial failure. J. Manag. Organ. 13 (4), 331-344.

Singh, S., Corner, P.D., Pavlovich, K., 2015. Failed, not finished: a narrative approach to understanding venture failure stigmatization. J. Bus. Ventur. 30 (1), $150-166$.

Smith, C.G., Smith, J.B., 2019. Founders' uses of digital networks for resource acquisition: extending network theory online. J. Bus. Res (forthcoming).

Smith, C.G., Smith, J.B., Shaw, E., 2017. Embracing digital networks: entrepreneurs' social capital online. J. Bus. Ventur. 32 (1), 18-34.

Stephens-Davidowitz, S., Pabon, A., 2017. Everybody Lies: Big Data, New Data, and What the Internet Can Tell us about Who we Really Are. HarperCollins, New York.

Tata, A., Martinez, D.L., Garcia, D., Oesch, A., Brusoni, S., 2017. The psycholinguistics of entrepreneurship. J. Bus. Ventur. Insights 7, 38-44.

Tausczik, Y.R., Pennebaker, J.W., 2010. The psychological meaning of words: LIWC and computerized text analysis methods. J. Lang. Soc. Psychol. 29 (1), $24-54$.

Ter Wal, A.L., Alexy, O., Block, J., Sandner, P.G., 2016. The best of both worlds: the benefits of open-specialized and closed-diverse syndication networks for new ventures' success. Adm. Sci. Q. 61 (3), 393-432.

Ucbasaran, D., Shepherd, D.A., Lockett, A., Lyon, S.J., 2013. Life after business failure: the process and consequences of business failure for entrepreneurs. J. Manag. 39 (1), 163-202.

Wennberg, K., Anderson, B.S., 2019. Editorial: enhancing the exploration and communication of quantitative entrepreneurship research. J. Bus. Ventur (forthcoming).

Wennberg, K., Wiklund, J., DeTienne, D.R., Cardon, M.S., 2010. Reconceptualizing entrepreneurial exit: divergent exit routes and their drivers. J. Bus. Ventur. 25 (4), 361-375.

Wiklund, J., Nikolaev, B., Shir, N., Foo, M.D., Bradley, S., 2019. Entrepreneurship and well-being: past, present, and future. J. Bus. Ventur. 34 (4), $579-588$.

Winkler, H.J., Rieger, V., Engelen, A., 2020. Does the CMO's personality matter for web traffic? Evidence from technology-based new ventures. J. Acad. Mark. Sci. 48, 308-330.

Wolfe, M.T., Shepherd, D.A., 2015. "Bouncing back" from a loss: entrepreneurial orientation, emotions, and failure narratives. Entrepreneurship Theory and Practice 39 (3), 675-700.

Wry, T., York, J.G., 2017. An identity-based approach to social enterprise. Acad. Manag. Rev. 42 (3), 437-460.

Youyou, W., Kosinski, M., Stillwell, D., 2015. Computer-based personality judgments are more accurate than those made by humans. Proc. Natl. Acad. Sci. 112 (4), $1036-1040$.

Zavyalova, A., Pfarrer, M.D., Reger, R.K., Shapiro, D.L., 2012. Managing the message: the effects of firm actions and industry spillovers on media coverage following wrongdoing. Acad. Manag. J. 55 (5), 1079-1101. 